\title{
Pensar las mediaciones hoy
}

Jesús Martin-Barbero

Para los que hoy hacen posible la Revista Mediaciones, deseándole una larga vida y mucho coraje para sostener las tensiones que conlleva en estos tiempos un pensamiento crítico y socialmente

emancipador

En el que constituyó el primer encuentro de estudiosos y escuelas de comunicación de América Latina, organizado por Hector Schmucler en la UAM-Xochimilco de la ciudad de México en 1978, presenté una ponencia en la que me atreví a invertir el sentido de la idea, ya entonces slogan, que hegemonizaba la visión critica, (la comunicación como proceso de denominación) para proponer el estudio de la dominación como proceso de comunicación. Que se apoyaba en el análisis de Paulo Freire sobre la opresión interiorizada por las sociedades latinoamericanas cuando "el oprimido vio en el opresor su testimonio de hombre" e insertaba ese análisis en la concepción gramsciana de la hegemonía como un proceso vivido, hecho no sólo de aparatos y fuerzas sino de sentido. Comprender la comunicación implicaba entonces investigar no solo las tretas del dominador sino también aquello que en el dominado trabaja a favor del dominador, esto es la complicidad de su parte y la seducción que se produce entre ambos. Junto con Gramsci fue Paulo Freire el que me enseñó a pensar la comunicación desde la cultura: a la vez como proceso social y como un campo de batalla cultural.

Inicialmente, el concepto de mediación procede de mi tesis de doctorado y en especial de la propuesta de Paul Ricoeur sobre mediación 
que produce el espesor de los signos, la que emerge en el reconocimiento del otro que implica el lenguaje y la que constituye nuestra relación al mundo como horizonte de emergencia del sentido. De ahí las tres partes que, como ejes de la reflexión, organizaban el texto de mi tesis: primero, las formas de objetivación de la acción en el lenguaje y las formas de objetivación del lenguaje como acción; segundo, la comunicación como emergencia del otro, el lenguaje como pregunta e interpelación; y, tercero, la auto-implicación, esto es la emergencia y constitución del sujeto en el cruce del lenguaje y la acción. Es del ámbito filosófico del que proviene el concepto de mediación que me ha permitido dibujar los mapas nocturnos para la reflexión y la investigación.

Pero no solo del pensamiento de P, Ricoeur sino también del de Maurice Merleu-Ponty en el que aprendí otras mediaciones claves: de la percepción con la expresión y de lo visible con lo invisible. Se trata de pensar la comunicación desde la experiencia originaria en que se constituye el mundo, especialmente en la experiencia constitutiva del arte, ese interfaz entre la percepción y la expresión, punto de vista desde el que el mundo toma forma y sentido. Una experiencia en la que el cuerpo propio deja de ser el instrumento de que se sirve la mente para conocer y se convierte en el lugar desde el que veo y toco al mundo o, mejor aún, desde el que siento cómo el mundo me toca, pues "estamos hechos de la carne del mundo". Pero el mundo que (es lo que) vemos, no se nos revela sin embargo mas que si aprendemos a verlo: la secreta conexión entre lo sensible y lo inteligible, entre lo visible y lo invisible, la invisibilidad profunda desde la que vemos. Pues la trama de los signos se espesa hasta llegar a insubordinarse contra la representación: los signos ya no son la versión exterior del pensamiento sino una materialidad sonora, visual, olfativa, que nos liga a la vida y a la expresividad histórica del pueblo, esa que emerge en el lenguaje. Ese concepto de mediación me permitirá introducir la ruptura con el mediacentrismo que resulta de la identificación de la comunicación con los medios, ya sea desde el culturalismo mcluhiano, según el cual los medios hacen la historia, o desde su contrario, el ideologismo althuseriano que hace de los medios un mero aparato de Estado. Desde uno u otro comprender la comunicación es estudiar cómo funcionan las tecnologías o los "aparatos" pues ellos hacen la comunicación, la determinan y le dan su forma. Curioso que, mientras en los países centrales ese mediacentrismo está siendo superado por el movimiento mismo de la reconversión industrial (que hace perder a los medios, y en especial a la televisión, su especificidad comunicativa al subordinar esa función a su nuevo carácter de elemento integrante de la producción y de la economía en general) sea en nuestros países donde los medios siguen fagocitando el sentido de la comunicación relegando a los márgenes del campo de estudio la cuestión de las prácticas, las situaciones y los contextos, de los usos sociales y los modos de apropiación. Pues la centralidad que hoy ocupan los medios resulta desproporcionada y paradójica en países con necesidades básicas insatisfechas en el orden de la educación o la salud como los nuestros, y en los que el crecimiento de la desigualdad atomiza nuestras sociedades deteriorando los dispositivos de comunicación, esto es cohesión política y cultural.

Fue por eso que llamé mapa nocturno a aquel con el que con el que busqué reubicar el estudio de los medios en la investigación de las matrices culturales, los espacios sociales y las operaciones comunicacionales de los diferentes actores del proceso. Y fue ese artesanal oficio el que guió la larga, cerca de diez años, investigación que recogió De los medios a las mediaciones, donde sinteticé así lo que entendía por mapa nocturno: "un mapa para indagar la dominación, la producción y el 
trabajo pero desde el otro lado: el de las brechas, el consumo y el placer. Un mapa no para la fuga sino para el reconocimiento de la situación desde las mediaciones y los sujetos, para cambiar el lugar desde el que se formulan las preguntas, para asumir los márgenes no como tema sino como enzima. Porque los tiempos no están para la síntesis, y son muchas las zonas de la realidad cotidiana que están aun por explorar y en cuya exploración no podemos avanzar sino a tientas o con sólo un mapa nocturno".

Hoy la comunicación aparece constituyendo una escena nueva de mediación y reconocimiento social, en la que las imágenes y representaciones de los medios al mismo tiempo que espectacularizan y adelgazan lo político, lo reconstituyen. Pues lo que estamos viviendo no es, como creen los más pesimistas de los profetas-fin-de-milenio, la disolución de la política sino la reconfiguración de las mediaciones en que se constituyen sus nuevos modos de interpelación de los sujetos y de representación de los vínculos que cohesionan la sociedad. Pensar la política desde la comunicación significa entonces poner en primer plano los ingredientes simbólicos e imaginarios presentes en los procesos de formación del poder. Lo que deriva la democratización de la sociedad hacia un trabajo en la propia trama de cultural y comunicativa de las practicas sociales y políticas. Ni la productividad social de la política es separable de las batallas que se libran en el terreno simbólico, ni el carácter participativo de la democracia es hoy real por fuera de la escena pública que construye la comunicación masiva. Entonces, más que en cuanto objetos de políticas, la comunicación y la cultura se convierten en un campo primordial de batalla política: el estratégico escenario que le exige a la política recuperar su dimensión simbólica -su capacidad de representar el vínculo entre los ciudadanos, el sentimiento de pertenencia a una comunidad- para

\section{Presentación}

enfrentar la erosión del orden colectivo.

La re-ubicación del estudio de la comunicación en el campo de la cultura -de sus matrices históricas, sus temporalidades sociales y sus especificidades políticasimplicó una primera des-territorialización conceptual que abrió ese estudio a la pluralidad de los actores y la complejidad de sus dinámicas. En el mismo impulso que viene de ese desplazamiento, de hecho crucial en los años '90, de re-territorilizar la comunicación: ahora como movimiento que atraviesa y des-coloca a la cultura. Pues el lugar de la cultura en la sociedad cambia cuando la mediación tecnológica de la comunicación deja de ser meramente instrumental para convertirse en estructural: la tecnología remite hoy no a la novedad de unos aparatos sino a nuevos modos de percepción y de lenguaje, a nuevas sensibilidades y escrituras, a la mutación cultural que implica la asociación del nuevo modo de producir con un nuevo modo de comunicar que convierte al conocimiento en una fuerza productiva directa. Y el lugar de la cultura en la sociedad cambia también cuando los procesos de globalización económica e informacional reavivan la cuestión de las identidades culturales -étnicas, raciales, locales, regionales- hasta el punto de convertirlas en dimensión protagónica de muchos de los más feroces y complejos conflictos bélicos de los últimos años, al tiempo que esas mismas identidades, más las de género y las de edad, están reconfigurando hondamente la fuerza y el sentido de los lazos sociales, y las posibilidades de convivencia en lo nacional.

Los cambios en el ámbito de la tecnicidad y la identidad, están reclamando imperiosamente pensar las mediaciones comunicativas de la cultura, esto es el trazado de un nuevo mapa que dé cuenta de la complejidad en las relaciones constitutivas de la comunicación en la cultura cuando los medios han pasado a constituir un espacio clave de condensación e intersección de 


\section{Megichariomes}

la producción y el consumo cultural, al mismo tiempo que catalizan hoy algunas de las más intensas redes de poder. De ahí la necesidad de afrontar el pensamiento único que legitima la idea de que la tecnología es hoy el "gran mediador" entre los pueblos y el mundo, cuando lo que la tecnología media hoy más intensa y aceleradamente es la transformación de la sociedad en mercado, y de éste en principal agenciador de la mundialización (en sus muy contrapuestos sentidos). La lucha contra el pensamiento único halla así un lugar estratégico no sólo en el politeísmo nómada y descentrador que moviliza la reflexión e investigación sobre las mediaciones históricas del comunicar sino también en las transformaciones que atraviesan los mediadores socioculturales, tanto en sus figuras institucionales y tradicionales -la escuela, la familia, la iglesia, el barrio- como en el surgimiento de nuevos actores y movimientos sociales que, como las organizaciones ecológicas o de derechos humanos, los movimientos étnicos o de género, in'zoducen nuevos sentidos de lo social y nuevos usos sociales de los medios. 